\title{
ETERNIZANDO TRAVESSIA: MEMÓRIAS DE FORMAÇÃO EM ÁLBUM DE VIAGEM
}

\section{ANA CHRYSTINA MIGNOT}

Universidade do Estado do Rio de Janeiro

RESUMO O texto se volta para a viagem da educadora católica Laura Jacobina Lacombe, em 1925, quando partiu do Rio de Janeiro para estudar no Institut Jean-Jacques Rousseau, em Genebra, que à época era o principal centro de produção e difusão da Escola Nova. Seus registros em pequenino caderno - um álbum de viagem - são vistos como uma narrativa autobiográfica, onde procurou fixar a importância desta primeira travessia em sua formação. No movimento de interpretar tais registros, procurou-se compreender na materialidade do escrito, as motivações, as redes de ideias e afetos bem como os desdobramentos da viagem em sua trajetória pessoal e profissional, marcada pelo afastamento da Associação Brasileira de Educação, após a publicação do Manifesto dos Pioneiros da Educação Nova, e tentativa de catolicizar as ideias escolanovistas.

Palavras-chave: Álbum de viagem. Laura Jacobina Lacombe. Institut Jean-Jacques Rousseau.

\section{ABSTRACT ETERNIZING CROSSINGS: TRAVELING ALBUM}

\section{FORMATION MEMORIES}

The text focuses on the journey of Catholic educator Laura Jacobina Lacombe in 1925, when she left Rio de Janeiro to study at the Institut Jean-Jacques Rousseau in Geneva, which at the time was the main center of production and diffusion of the New School. Her records in a small notebook - a travel album - are seen as an autobiographical narrative, where she sought to establish the importance of this first crossing in her formation. In the movement to interpret such records, it was sought to understand in the materiality of the writing, the motivations, networks of ideas and affections as well as the unfolding of the journey in her personal and professional trajectory, marked by the withdrawal of the Brazilian Association of Education, after publication of the Manifesto of the Pioneers of New Education, and attempt to catholicize the New School's ideas.

Keywords: Travel album. Laura Jacobina Lacombe. Institut Jean-Jacques Rousseau. 


\section{RESUMEN ETERNIZANDO TRAVESÍA: MEMORIAS DE FORMACIÓN}

\section{EN ÁLBUM DE VIAJE}

El texto se vuelve hacia el viaje de la educadora católica Laura Jacobina Lacombe, en 1925, cuando partió de Rio de Janeiro para estudiar en el Institut Jean-Jacques Rousseau, en Ginebra, que en aquella época era el principal centro de producción y difusión de la Escuela Nueva. Sus registros en un cuaderno pequeño - un álbum de viaje - son vistos como una narrativa autobiográfica, donde intentó fijar la importancia de esta primera travesía en su formación. En el movimiento de interpretar tales registros, se procuró comprender en la materialidad del escrito, las motivaciones, las redes de ideas y afectos, así como los desdoblamientos del viaje en su trayectoria personal y profesional, marcada por el alejamiento de la Associação Brasileira de Educação, después de la publicación del Manifesto dos Pioneiros da Educação Nova, y la tentativa de catolizar las ideas escolanovistas.

Palabras clave: Álbum de viaje. Laura Jacobina Lacombe. Institut Jean-Jacques Rousseau.

Como tantos educadores que registraram suas viagens em cartas, cartões postais, diários, notas de viagem, memórias e relatórios, Laura Jacobina Lacombe também lançou mão da escrita para documentar a experiência, provar o vivido, evitar o esquecimento. Em um pequenino caderno sem pauta, costurado, com folhas já amareladas que denunciam a passagem do tempo, seu álbum de viagem parece ter sido escrito, como diário, no dia do acontecimento e, em outros, lembra notas de viagem que resultam de um esforço de distanciamento para selecionar o mais significativo de sua primeira passagem pelo velho mundo.

Longe de ser uma escrita íntima, como diários que são produzidos na surdina, em recolhimento, distante de olhares alheios, o álbum de viagem parece ser uma escrita coletiva, pois algumas páginas trazem mensagens e assinaturas daqueles que conheceu nos países por onde passou, como a Itália, a França, Portugal e Suiça, especialmente no Institut Jean-Jacques Rousseau, algumas delas incompreensí- veis, mas que sinalizam tanto para sua convivência com renomados cientistas como com estudantes de diferentes nacionalidades que se dirigiam àquele instituto em busca de novos conhecimentos sobre a infância e os modernos métodos de ensino.

Preservado como "objeto-relíquia", que na acepção de Orest Ranum (1991) contribui para evocar amores e amizades e que funciona como lembrança materializada, o álbum de viagem de Laura Jacobina Lacombe expressa a tentativa de legar uma dada imagem que tinha de si mesma, do trabalho que desenvolvera e do relevante papel formador desta experiência em sua trajetória pessoal e profissional, o que a levou a comentar anos depois: "Dizem que a vida começa aos quarenta: a minha começou quando fiz a minha primeira viagem à Europa", e que me fez lembrar da afirmativa de Antonio

1 Ver discurso proferido por Laura Jacobina Lacombe em solenidade comemorativa do centenário de nascimento de Edouard Claparède, promovida pela Associação Brasileira de Educação, em 1973, no Rio de Janeiro. A este respeito ver MIGNOT (2016a, 2016b). 
Viñao sobre o papel educativo das viagens “[...] todos los viajes educan, aunque solo sea por abrir al viajero a uma realidad diferente a la suya. Sólo que unos educan más que otros, o de forma diferente a otros [...]"2 (2007, p. 15).

Folheio as páginas do pequenino caderno onde existem marcas que denunciam ter sido visto, folheado, lido, comentado, admirado, publicizado, não só durante a viagem, mas ao longo dos anos, convencida de que nele encontrarei pistas de como a educadora católica, se aproximou e se apropriou de princípios e práticas escolanovistas que, mais tarde, permitiram sua participação na "[...] triagem da má pedagogia e estabelecer os limites de aceitabilidade das propostas escolanovistas [...]" (CARVALHO, 1998, apud STRANG, 2008, p. 86). Enquanto observo as anotações, decido me ater aos registros de sua permanência em Genebra procurando interpretar o álbum de viagem como uma narrativa autobiográfica, onde procurou fixar a importância desta primeira travessia em sua formação.

\section{Registrar parar lembrar}

Cartas, prospectos, álbuns de fotografias e fotografias avulsas, repousam dentro de uma pasta de cartolina, juntamente com o pequenino caderno, seu álbum de viagem. Guardada em meio à farta documentação da Organização Mundial de Educação Pré-Escolar $(\mathrm{OMEP})^{3}$ instiga a folhear páginas amareladas com um olhar de curiosidade e estranhamento para cada anotação e ilustração deixadas por Laura Jacobina Lacombe, que presidiu a entidade desde 1955, depois de ter atuado na Associação Brasileira de Educação, a partir de

2 “...] Todas as viagens educam, ainda que seja por abrir ao viajante uma realidade diferente da sua. Algumas educam mais que outras, ou de forma diferente de outras [...]" (VINÃO, 2007, p. 15)

3 Entidade fundada no Brasil em 1955, que reuniu várias lideranças católicas, realizando o primeiro levantamento da educação pré-escolar do país.
1924, onde protagonizou forte polêmica com os pioneiros que defendiam a escola laica, a coeducação e o ensino público gratuito, o que a levou a sair da mesma para participar da fundação da Associação de Professores Católicos do Distrito Federal, em 1931, na qual, como lembra Bernadete Stang, procurou se inserir no propósito mais amplo da associação que visava "[...] adotar a Escola Nova, naquilo que não se contrapõe aos dogmas católicos e às leis eclesiásticas [...]" (2008, p. 73). Por intermédio de congressos, cursos, conferências, boletins e revistas, a associação atuou no sentido de "[...] regrar a sedução exercida pelo escolanovismo sobre o professorado [...]", sedução esta que atingiu, "[...] não somente as práticas dos professores das escolas católicas, mas também do professorado católico nas escolas públicas [...]", como assinala Marta Carvalho (2002, p. 290).

Mesmo sem nenhum indício de classificação que a identifique, após uma primeira aproximação, é possível observar que a pasta reúne documentos de viagens de uma mulher que, desde 1925, buscou aprimorar sua formação em importantes centros de produção e difusão do pensamento educacional no país e no exterior, legitimando-se, assim, como interlocutora capaz de difundir a sua versão da nova pedagogia, como se pode ver na moção de pesar por ocasião de seu falecimento, em fevereiro de 1990, proposta pela deputada estadual Yara Vargas:

Seu colégio - o famoso Colégio Jacobina -, com sede num casarão de Botafogo, foi um marco na formação de gerações inteiras de jovens. A excelência de seu ensino deveu-se, totalmente, ao empenho e à firmeza desta professora. [...]

Já com sua vida direcionada para o que foi a sua paixão - Educação -, aprimorou-se no célebre 'Institut Jean-Jacques Rousseau', em Genebra, na Suiça. Lá, foi aluna de Claparède e Pierre Bovet, e do genial Jean Piaget, sábio cujas teorias são base da educação moderna. 
Diplomou-se na Universidade de Louvain, na Bélgica, tendo ocupado, ao longo de sua vida, os mais ilustres cargos na área da Educação.

Foi Presidente de Honra da OMEP no Brasil, que é a Organização Mundial do Ensino Pré-Escolar, desde 1955. Secretária e depois Presidente da Comissão de Educação e Cultura da Organização das Entidades não Governamentais do Brasil (OENG) por dez anos. Diretora-Fundadora da Faculdade de Educação Jacobina. Secretária Geral da Associação de Educação Católica do Brasil por dez anos.

Seu Colégio foi o primeiro no Brasil inscrito na UNESCO, recebendo, por isso, diploma e medalha comemorativa dos 25 anos dessa participação.

Mas o título que, temos certeza, mais lhe afagou o coração foi, inegavelmente, a Direção-Geral do Colégio Jacobina, onde, desde 1936, era, para todos, a D. Laura. ${ }^{4}$

Tomo primeiramente as cartas enviadas à educadora, preservadas na mesma pasta. Detenho-me em papéis timbrados - Bureau International d'Education, Université de Genéve/Institut des Sciences de l'Education, Ligue Internationale pour l'Education Nouvelle, Pour l'Ere Nouvelle, Ecole des Roches, Departement de l'Instrution Publique de Genève, Ligue des Sociétés de la Croix-Rouge, Société des Nations/Institut International de Cooperation Intellectuelle, École Primaire Súperieure de Jeunes Filles, École Normale Primaire d'Instrutices de la Charente-Inférieure, École de l'Ermitage, École Decroly, The Austro-American Institute of Education, Department of Education of Sidney, e Commitee of Russian Towns Union - que sinalizam para o lugar social ocupado pelos remetentes que escreveram de variados países: Suiça, França, Bélgica, Áustria, Austrália, Estados Unidos, Tchecoslováquia, dentre outros.

Ao longo dos anos, a maior parte, foi remetida da Suiça, o que se justifica, certamen-

4 Documento datilografado, com timbre da Assembleia Legislativa do Estado do Rio de Janeiro, datado de 20 de fevereiro de 1990. te, pelas razões apontadas por Angel Moreu (2016), quando realça o protagonismo deste país, particularmente na aposta no pacifismo e neutralidade, que the permitiram sediar, no entreguerras, uma grande quantidade de organismos internacionais e, atuar na produção e difusão de ideais da Educação Nova, desde 1899, quando Adolphe Ferrière criou o Bureau International des Écoles Nouvelles, quando Edouard Claparède fundou o Institut Jean-Jacques Rousseau, em 1912, com a Maison des Petits, como escola anexa, no ano seguinte, ou em 1925, com a constituição do Bureau International d'Education, liderado por Edouard Clapearèd, Pierre Bovet e Adolphe Ferrière, o que, no entendimento do autor, transformou o Instituto Jean-Jacques Rousseau, “[...] em lugar de peregrinação para profissionais da educação de toda a Europa [...]" (MOREU, 2016, p. 57).

Enquanto examino inúmeras fotografias, algumas delas agrupadas em álbuns, com legendas ou anotações no verso, encontro Laura Jacobina Lacombe mundo afora e me dou conta de que nelas não constam registros de todas as suas participações em eventos internacionais: Congresso Internacional de Educação Moderna (LOCARNO, 1927), na Missão de Estudos da Associação Brasileira de Educação para estágio no Teacher's College, (Nova York, 1929), no Curso na Université Catholique de Louvain (Bruxelas, 1933), em Congresso da Union International Catholique de l'Infance, (Bogotá, 1945), no Seminário Regional de Educação das Organizações Não-Governamentais (ONU), (1948), no Congresso Internacional Católico (Estraburgo, 1961), na Assembleia Mundial da Organização Mundial de Educação Pré -Escolar, em 1956, 1958, 1960, 1962, 1964, 1968 e 1970, realizadas em Atenas, Bruxelas, Zagreb, Londres, Estocolmo, Paris e Washigton, quando representava o Brasil. 
Detenho-me, finalmente, no pequenino caderno onde registrou o vivido, e encontro dedicatórias, assinaturas, fotografias, desenhos, feitos por Laura ou deixados por amigos durante sua primeira viagem à Europa, em 1925, quando partiu para estudar no Institut JeanJacques Rousseau, que à época se constituía em principal destino dos educadores que buscavam se aproximar do conhecimento científico e dos métodos de ensino mais adequados ao desenvolvimento psicológico infantil.

\section{Motivações para partir}

Enquanto educadores como Anísio Teixeira e Cecília Meireles descreveram em diários e em crônicas publicadas em jornal o momento da partida e a travessia pelo mar, Laura não deixou documentos que permitam interpretar suas inquietações, medos e expectativas, enquanto se distanciava do Rio de Janeiro ou se aproximava do porto de destino. Uma única fotografia registra a viagem a bordo do navio Alba, que a levou à Europa para estudar.

Aliás, no álbum de viagem, as fotografias têm uma grande força na narrativa construída por Laura sobre esta travessia. Coladas ao longo das páginas, resultam de uma tentativa de contar sua própria aventura. Anotadas ou legendadas, os pequenos textos que as acompanham parecem ter a intenção de guiar o olhar do observador para o que deve ser armazenado, retido, valorizado. Deste modo, se pode entender a escolha de Pierre Bovet, na primeira página, quando começa a registrar sua chegada em Genebra, onde escreveu, em francês, ser ele o diretor do Instituto Jean-Jacques Rousseau, educador que, segundo Jean Houssaye, teria ficado apagado no processo de difusão de ideias pedagógicas, como outros que criaram ou propagaram determinadas propostas e até mesmo termos como Escola Ativa, que parecia unificar a todos:
Ora, este termo apareceu subrepticiamente e de forma anônima em Genebra, provavelmente escrito por Bovet, em 1917. Ele não vem de expoentes famosos como Claparède ou Ferrière (mesmo se este último fez dele sua marca registrada). Ele vai tomar o lugar da Arbeitsschule alemã de Kerchenstein e do seu trabalho produtivo (1895-1920). O que há de certo, é que a escola ativa vai funcionar como mote de uma ruptura com a chamada 'escola atual tradicional'. Apesar de que, segundo Hameline, é entre estes 'tradicionais' que poderíamos encontrar as suas concepções iniciais (colocar no centro a atividade do aluno e não mais a do mestre). 0 alemão Herbart (1824) e o francês Marion (1888) podem muito bem ser reabilitados como os iniciadores desconhecidos da escola ativa suiça. Isto funciona como um paradoxo na medida em que os pais desta noção fizeram, no seu tempo, uma oposição veemente a tudo o que estes autores representam no plano pedagógico, indo até fazer deles seus inimigos privilegiados. (2007, p. 297)

A seguir, uma fotografia de Edouard Claparède em seu gabinete, cercado de livros e papéis sobre a mesa, como se estivesse a refletir sobre as ideias que o consagraram e que o levaram a defender "uma escola sob medida", "na qual nenhuma criança poderia ser obrigada a realizar atividade que não estivesse em consonância com seu grau de amadurecimento" (MOREU, op.cit. p. 58). No entanto, não aparece no álbum de viagem nenhuma fotografia legendada como sendo da Maison des Petits, por ele criada e que “[...] chegou a ser um autêntico observatório da infância e um laboratório de experiência metodológica onde se preparavam para a vida mais de 50 crianças de 3 a 9 anos, e para sua futura atividade, umas 20 jovens educadoras [...]" (idem), onde não existiam métodos fixos, nem horários, nem programas pré-estabelecidos, de modo a permitir que a “[...] criança descubra seu próprio caminho [...]" (idem. p. 60). 
Figura 1 - Fotografias de Pierre Bovet e Edouard Claparède no álbum de viagem. Genebra, 1925.

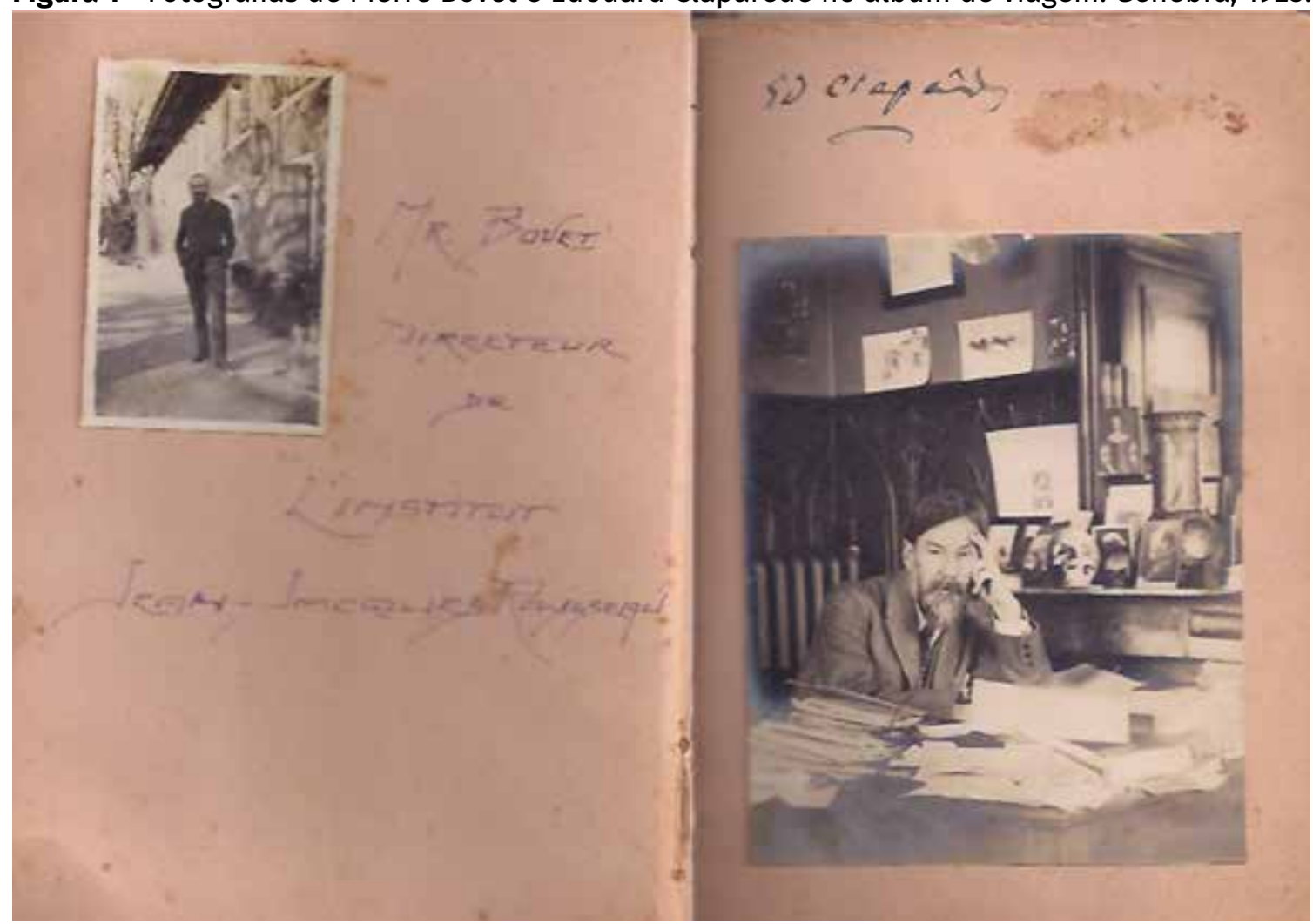

Fonte: Álbum de viagem de Laura Jacobina Lacombe, 1925. Acervo OMEP, Rio de Janeiro.

Mas, além dos expoentes do Instituto JeanJacques Rousseau, Laura seleciona imagens de prédios, como a Universidade de Genebra, a residência de Claparède, a Maisons des Etudiantes, onde se hospedou, e mesmo sua mesa de trabalho. Apesar de aparecer em algumas fotografias, na saída da Universidade, em passeios pelo Mont Salève, em atividades na École de Activitè Manuelle, compõe seu álbum de viagem com registros de colegas de curso, que, como ela, se deslocaram para aquele que seria, no entendimento de Edouard Claparède um "centro de referência", um "centro de investigações", um "centro de informações" e um "centro de propaganda" da Escola Nova, o que levou seus idealizadores não só a receberem visitantes mas a viajar pelo mundo para disseminar a nova pedagogia. ${ }^{5}$

Como a Suiça era considerada a "Meca da pedagogia", pois "o imenso movimento da

5 A respeito do papel do Institut Jean-Jacques Rousseau, na visão de seus idealizadores, consultar Claparède (1959).
Figura 2 - Professores e alunos do Instituto JeanJacques Rousseau. Genebra, 1925.

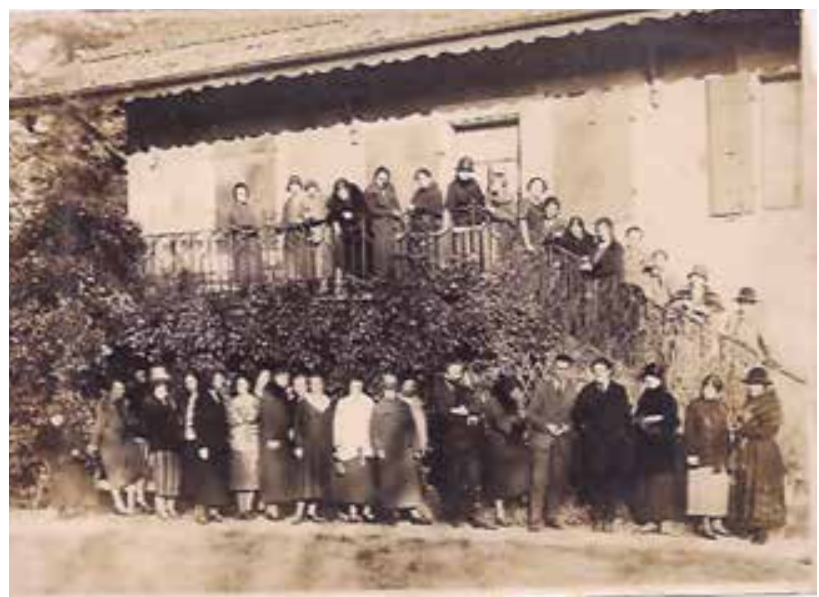

Fonte: Álbum de viagem de Laura Jacobina Lacombe, 1925. Acervo OMEP, Rio de Janeiro.

Educação Nova terá seu epicentro no Instituto Jean-Jacques Rousseau de Genebra", como lembra Jean Houssaye (op. cit., p. 305), onde os pedagogos ali reunidos atuaram fortemente na produção e difusão do ideário escolanovista como "grandes viajantes, fisicamente, intelectualmente e coletivamente" (op. cit, p. 298), não é de se estranhar que tenha sido este o 
destino escolhido. Segundo Andrea Caruso, a viagem surgiu da necessidade de auxiliar a mãe - Isabel Jacobina Lacombe - na direção do Colégio Jacobina:

A família Jacobina, tendo consciência de que a jovem Laura ainda não estava preparada para substituir sua mãe no oficio de maior responsabilidade dentro instituição educacional, começou a pensar em uma solução plausivel para que Laura pudesse descansar dessa função que tomava tanto seu tempo, principalmente a partir do crescimento do colégio nos últimos anos. Por isso, em 1924, Isabel Jacobina Lacombe cogitou em trazer uma professora da Europa para tomar conta do colégio, mas o amigo Carneiro Leão, diretor da Instrução Pública, sugeriu que ao invés de ela mandar vir alguém de fora, que mandasse Laura à Europa (2006, p. 58).

\section{Mensagens que ficam}

Mensagens deixadas no álbum de viagem, além das assinaturas de colegas e professores com os quais conviveu - Jean Piaget, Pierre Bovet, Jean-Louis Claparède, Madeleine Fauraire, Irma Heller, Max Hochstaether, Regine Merlin, Suzanne Engelson, Gertrud Elsinger, Ida Bringeer - em Genebra, sugerem que Laura solicitava tais registros para que comprovassem o vivido, de modo que não fosse possivel esquecer, para sempre recordar.

Em várias páginas, companheiros de diferentes países que naquele momento se dirigiam ao Instituto Jean-Jacques Rousseau, em busca de inovações, testemunham o sentido de atravessar terras e mares, lançando mão de expressões que sugerem o compromisso ali assumido de estimular, disseminar, espalhar o aprendido e o sonho compartilhado: "Conhecer a criança, descobrir suas energias latentes e levá-la a descobri-las - eis a verdadeira obra do pedagogo - seja em Genebra ou no Brasil. Com a amizade de Suzanne E. Institut J.-J. Rousseau, 20 de março de 1925."

Figura 3 - Mensagens no álbum de viagem. Genebra, 1925.

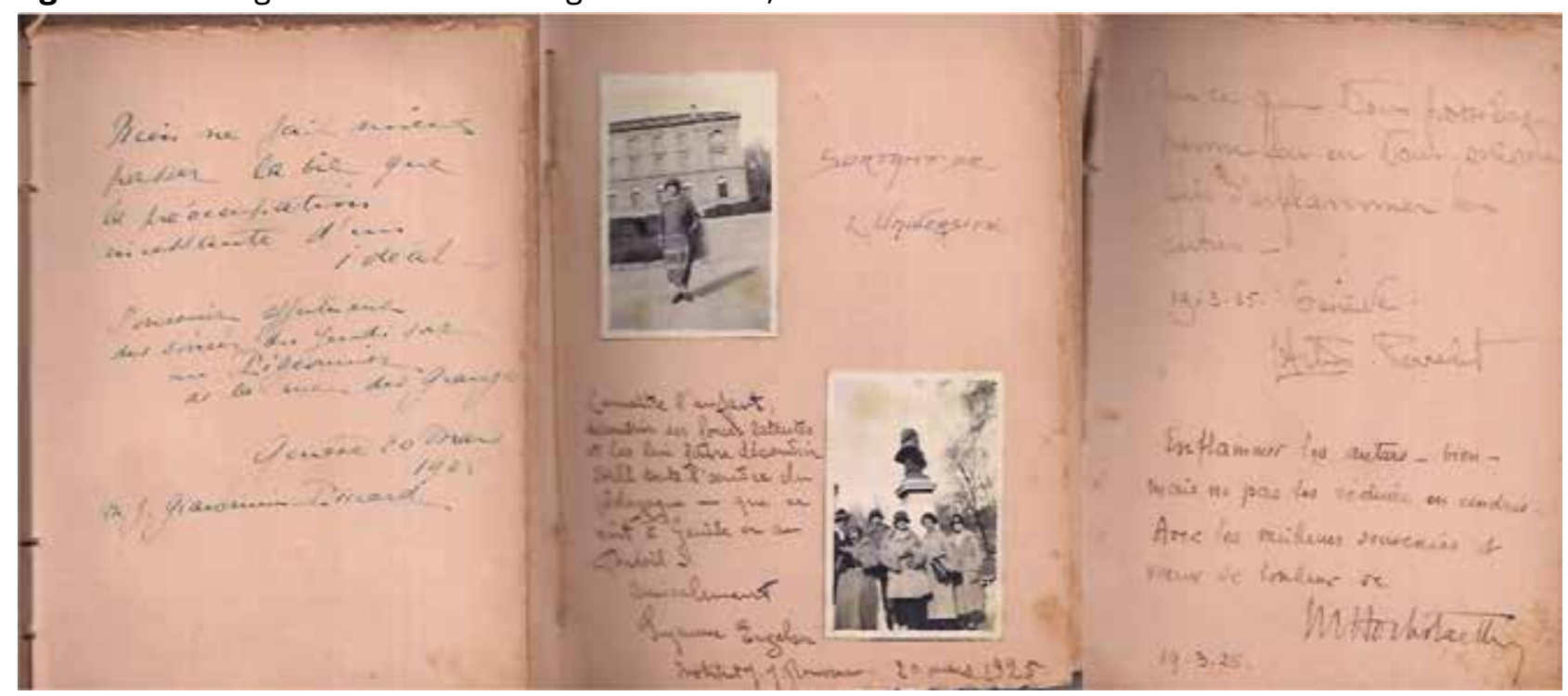

Fonte: Álbum de viagem de Laura Jacobina Lacombe, 1925. Acervo OMEP, Rio de Janeiro.

Outras, falam claramente de ideais ou lançam mão de metáforas para acentuar a missão dos educadores e educadoras ali reunidos: "O que há de mais agradável na vida é a preocupação incessante com um ideal"; "Aquilo que você possui pegue fogo em você mesma a fim de inflamar os outros" e ainda "Inflamar os outros - excelente - mas atenção para evitar reduzi-los a cinzas". ${ }^{6}$ Certamente, pelo que se pode depreender do discurso pronunciado por

6 As duas primeiras mensagens foram escritas em 20 de março de 1925 e as outras em 19 de março de 1925. 
Laura Jacobina Lacombe, em 1973, por ocasião das comemorações do centenário de Claparède, promovida pela Associação Brasileira de Educação, aqueles que deixaram mensagens em seu álbum de viagem foram aqueles com os quais conseguiu estreitar sua rede de ideias e afetos, durante a viagem:

Faz quase cinquenta anos, recebemos boa acoIhida nas salas do 'Institut Jean Jacques Rousseau', que frequentávamos o 'Vieux Champel', onde se achava a mansão em que residia o Professor Claparède, em cujo parque fervilhava a alegria da 'Maison des Petits'. Éramos uns trinta e seis alunos de quatorze países diferentes, todos cativados pelo acolhimento dos mestres Bovet e Claparède que, unidos como dois irmãos, realizaram, felizes, o seu sonho de renovação da pedagogia. (LACOMBE, 1973, s/p)

Passo os olhos pelos textos, com letras muitas vezes de difícil leitura, e encontro textos escritos e assinados por Pierre Bovet e Jean Piaget: “Conhecer a criança, conhecer-se a si mesmo - esses dois esforços apoiam-se mutuamente, do mesmo modo que a educação de si é indispensável à educação de outrem. “'Para doar-se, é necessário ter plena posse de si'. 'Meu desejo é que o homem se promova a si mesmo, contanto que seja [...] o servidor de todos'. Essas palavras sensatas de Vinet não serão destoantes neste livro", escreveu Bovet; "'Tenho aprendido tudo o que eu sei com as crianças e, cotidianamente, continuo aprendendo com elas', disse Froëbel", comentou Piaget, mensagens com claras alusões a educadores com os quais, provavelmente, atribuíam influência sobre si mesmos. Um desenho de Claparède, que retrata uma atividade do grupo de educadores, em atividade ao ar livre, também dá conta de que tinham sido por ela escoIhidos, na medida em que justificavam sua ida ao Instituto Jean-Jacques Rousseau para aprimorar sua formação, aprender, experimentar, comparar, fundamentar sua prática educativa, enfim. ${ }^{7}$

Figura 4 - Mensagens de Pierre Bovet e Jean Piaget. Ilustração de Edouard Claparède, no álbum de viagem. Genebra, 1925.

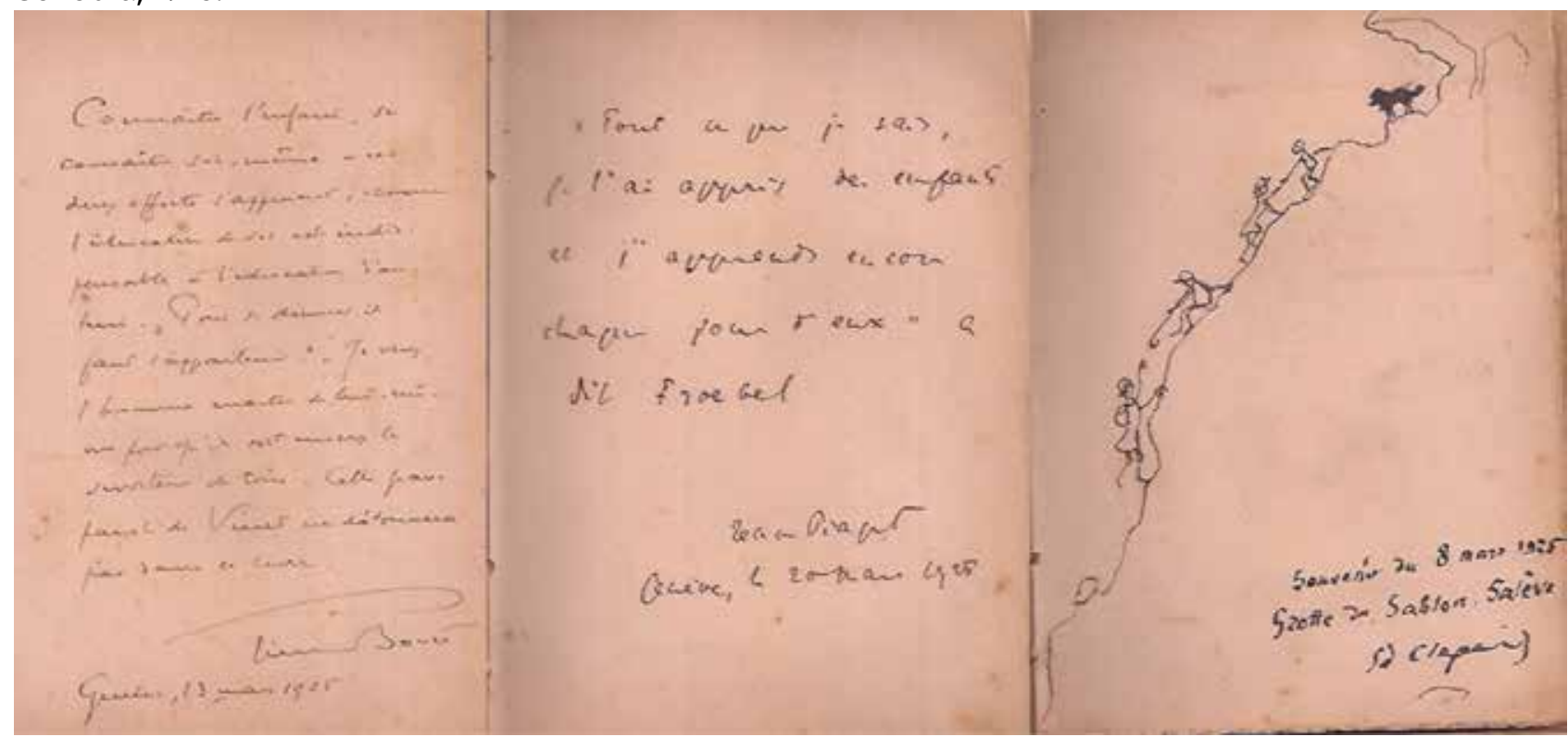

Fonte: Álbum de viagem de Laura Jacobina Lacombe, 1925. Acervo OMEP, Rio de Janeiro.

Laura não era a primeira brasileira a participar dos cursos ministrados pelo Instituto, pois como afirmou Martine Ruchat (2008), os contatos de Claparède com o Brasil se davam
7 O álbum de viagem traz mensagens escritas por pessoas com as quais conviveu em outros países durante esta viagem, com algumas assinaturas incompreensíveis, e é encerrado pelas portuguesas Maria Christina de Gonta Colaço e Branca de Gonta Colaço, em maio de 1925. 
desde a formação da primeira turma, que teve dentre os 22 alunos franceses, portugueses, suiços, espanhóis e ingleses, um brasileiro Francisco Lins, professor e diretor da Escola Normal de Juiz de Fora, que participaram das aulas ministradas por ele, por Pierre Bovet, François Naville, Alice Descourdes e Mina Audemars da Maison de Petits, que funcionava como uma escola de aplicação do Instituto Jean-Jacques Rousseau. Mas, em carta remetida por Pierre Bovet, por ocasião do falecimento de Claparède, em 1946, se deu conta de que não mais existiam alunos da América do Sul no Intituto Jean-Jacques Rousseau, mas o professor Ferrière continuava ativo e generoso e Jean Piaget trabalhava mais do que nunca (LACOMBE, 1973).

Enquanto recolhia estas mensagens que pareciam dedicatórias, Laura não imaginava que, em dois anos, como representante da Associação Brasileira de Educação, voltaria a rever seus mestres, em Locarno, no Congresso de Educação Moderna. Não poderia, também, supor que receberia em 1930, no Rio de Janeiro, Edouard Claparède, que visitaria, na mesma ocasião, Minas Gerais, onde Helena Antippoff uma das suas mais importantes colaboradoras e que desde o ano anterior atuava na Escola de Aperfeiçoamento, destinada à formação de professores -, que já the avisara por cartas, segundo Martine Ruchat (op. cit), ser ele o "grande inspirador da educação nova", pois não encontraria no Brasil um único compêndio de Psicologia e Pedagogia que não tivesse o reconhecimento da importância de suas investigações.

Enquanto colava fotografias e recolhia assinaturas e mensagens, em seu álbum de viagem, deixava registrado o início de seu processo de legitimação no campo educacional em constituição, colocando-se em seu retorno como uma interlocutora credenciada para opinar a respeito de livros e leituras, cinema, imprensa, relação pais e professores, no interior da Associação Brasileira de Educação ${ }^{8}$ e, ao mesmo tempo, como a educadora escolhida para propagar as atividades do Bureau International d'Education, como se pode ver no I Conferência Nacional de Educação, promovida pela entidade, em Curitiba:

Membro muito ativo da Associação Brasileira de Educação, Laura Lacombe havia mesmo atuado como emissária do BIE na Primeira Conferência Nacional de Educação promovida pela $A B E$, em 1927, apresentando, no evento, uma memória sobre o Bureau que foi lida em Sessão Plenária. A leitura dessa memória teria mesmo ensejado a oportunidade de inúmeras novas adesões à instituição suiça, por intermédio de seu então correspondente brasileiro, Lourenço Filho (CARVALHO, 2007, p. 289).

\section{Desdobramentos da travessia}

Curiosamente, no álbum de viagem, não encontro mensagens de Adolphe Ferrière, com quem Laura manteve correspondência a partir de 1927, e com o qual, assumiria, por escrito, o compromisso de ajudá-lo na tarefa de propagação das ideias de Escola Ativa, na medida em que se tornou importante elo de ligação com o educador, quando ele decidiu visitar a América do Sul, em 1930. ${ }^{9}$ Em carta enviada em 09 de janeiro de 1929, em papel timbrado da revista Pour l'Ere Nouvelle ${ }^{10}$, Ferrière se dirigia a Lau-

8 Sobre a participação de Laura Jacobina Lacombe na Associação Brasileira de Educação, examinar a documentação da Secção de Cooperação da Família. Ver também Mignot (2002).

9 Sobre a viagem à América do Sul consultar Soler (2016). Ver também Toro (2016) que trata particularmente da viagem ao Chile.

10 Sobre o papel desempenhado por Adolphe Ferrière na difusão do escolanovismo, consultar Marta Chagas de Carvalho, chama a atenção para quando se dedica ao exame da revista Pour l'Ere Nouvelle, órgão francófono da Ligue International de l'Education Nouvelle, fundada em 1921, por ocasião do I Congresso Internacional de Educação Católica, em Calais, promovido pelo New Educational Felowship e pelo Bureau International des Écoles Nouvelles. Segundo a autora, por esta revista, que dividia com a The New Era e Das Werdenda Zeitalter, inglesa e alemã, respectivamente, o papel de porta voz da Liga, em especial, como ór- 
ra, comunicando da realização sua viagem, do desejo de desenvolver atividades no Brasil,"1 e da necessidade de viabilizar financeiramente deslocamentos e diárias, o que poderia ser feito se fosse possivel obter convite de órgão oficial, bem como dos motivos que o levaram a aceitar os pedidos para percorrer diferentes países:

Estimada Senhorita,

Quase todos os Estados da América do Sul estão adotando praticamente os métodos da Escola Ativa e, em geral, aqueles relacionados com a Escola Nova.

Recentemente, o Sr. Alberto Alvares veio buscar os nossos melhores professores da Europa para integrá-los na Escola Normal Superior do Rio de Janeiro. Chamo a atenção também para as viagens do Dr. Decroly a Bogotá e do Sr. Lorenzo Luzuriaga a várias cidades da América do Sul.

Esse é o motivo pelo qual decidimos aceitar os vários pedidos que nos foram dirigidos da América do Sul para fazermos uma turnê de conferências a fim de cristalizar as energias orientadas para a Educação Nova, além de apresentarmos a seu respeito, simultaneamente, uma definição precisa para afastar os perigos dos ignorantes entusiastas que não deixam de ser desastrados. Estaríamos disponíveis para fazer essa viagem de novembro de 1929 a março ou abril de 1930. [...]

Estarei em condições de dar conferências sobre os seguintes temas:

A coeducação mista.

As Escolas Novas no campo (educação física e social).

A Escola Ativa.

Os centros de interesse.

gão responsável pelos contatos com a América Latina, os relatos de viagens ganhavam espaço na medida em que propagavam o sucesso do movimento que pretendia fazer da escola um importante espaço de transformação social, especialmente a partir de 1925, quando Ferrière assume a posição de redator chefe, Paul Faucounnet o de redator para a França, e Ovide Decroly o de redator para a Bélgica.

11 A viagem de Adolphe Ferrière ao Brasil se deu na mesma época em que eclodiu a revolução de 1930, impedindo-o de desembarcar no porto do Rio de Janeiro. Consultar, a respeito, Peres (2002) e Carvalho (2007).
A disciplina segundo a psicologia do subconsciente e o self-government.

0 caráter e os tipos psicológicos.

A educação da mulher e a preparação materna.

Por gentileza, faça a análise de meu pedido e envie-me sua resposta o mais rapidamente possivel a fim de que, tendo em conta a demora do correio para a América do Sul, ela seja entregue antes da nossa partida. O importante é, sobretudo, a tomada de decisão, ou seja, os recursos financeiros.

Queira aceitar, estimada Senhorita, meus sinceros cumprimentos.

Ad. Ferrière

P.S. Estou também disponivel para elaborar, junto às autoridades competentes, a reformulação da legislação escolar no que diz respeito aos programas e métodos, adaptando as exigências da ciência moderna às condições especiais do país. - Aliás, no domingo passado, 6 de janeiro, o Sr. Alberto Alvares voltou a me confirmar que faria diligências para me enviar um convite - provavelmente, em março de 1930.

Dentre os educadores que conheceu em Genebra, parece ter sido Ferrière o escolhido por Laura para discutir suas dúvidas sobre temas que a mobilizavam em seu afã por "fomentar a verve religiosa do professorado e prestar esclarecimento sobre a Escola Nova, mostrando até que ponto era aceitável e que parte dela precisava ser avaliada", como lembra Bernadete de Lourdes Streisky Stang (2008, p. 67), ao examinar o papel da imprensa católica. Pelas respostas do educador, particularmente em carta datada de 10 de julho de 1929, é possível deduzir que ela não se limitou a absorver as ideias de renovação educacional que circulavam a partir da Suiça. Além de relatar, aplaudir e propagar o que viu, ouviu e observou, não se intimidou em criticar as propostas que emergiam no bojo do movimento renovador e que colidiam com as suas concepções religiosas, o que o obrigou a esclarecer na missiva também timbrada da revista Pour l'Ere Nouvelle: 
Estimada Senhorita,

Acuso a recepção, no devido tempo, de sua carta de 16 de maio, mas a razão pela qual só lhe respondo hoje é porque eu a enviei à Sra. Hauser.

Com efeito, a senhorita declara em sua carta 0 seguinte: "Recebi os impressos enviados pelo Groupe Français d'Education Nouvelle; tenho a deplorar que haja aí alusões ao ensino religioso: para evitar qualquer mal-entendido, seria preferivel não abordar esse campo".

Perguntei à Sra. Hauser qual era o conteúdo desses impressos. Ela deu-me a seguinte resposta: "Reli nossos documentos de propaganda para o Groupe e procurei, em vão, nesses textos o que teria causado a inquietação da srta. Lacombe. A srta. Flayol e eu própria teríamos tomado a precaução de evitar qualquer alusão que pudesse parecer sectária e que, aliás, não teria cabimento algum".

Sei que a srta. Flayol e o Groupe Français d'Education Nouvelle, precisamente para estarem em condições de exercer uma ação sobre os professores da escola laica, não levam em conta o que possa parecer relacionado a crenças religiosas. Assim, peço-lhe encarecidamente o favor de me indicar os aspectos a que se refere.

Convém, além disso, distinguir relativamente ao princípio fundamental de nossa Ligue entre o triunfo do espírito e as doutrinas materialistas frequentemente associadas a uma propaganda de extrema esquerda. A atitude da nossa Ligue é nitidamente favorável ao triunfo do espírito. Se a preparação das crianças para esse autodomínio em nome do espírito é chamada religiosa, nesse caso, reconheceremos sem dúvida a prioridade a essa forma de religião. No entanto, ela é universal e predominante em relação a todas as crenças religiosas particulares, incluindo o budismo e o confucionismo, sem confundir-se com nenhuma delas. Aliás, a srta. conhece meus livros em que não me privo de insistir sobre esse ponto. [...]

Ad. Ferrière

Sem acesso, ainda, ao conjunto das cartas escritas por Laura, percebo nas respostas de Ferrière que, fiel ao seu apostolado em favor de uma nova era que se construiria, segundo Soler (2016), a partir dos princípios do paido- centrismo, do pacifismo, do cosmopolitismo, do naturalismo, do cientificismo, do humanitarismo e do espírito liberal de corte democrático, ele não se furtou de opinar sobre temas que mobilizaram os educadores católicos e Laura, em especial, o que a levou e a seu grupo a romper com a Associação Brasileira de Educação, em 1932, quando foi lançado o Manifesto dos Pioneiros da Educação Nova.

Em 1973, quando Laura Jacobina Lacombe - então educadora reconhecida, já autora de três livros - Moral cristã e educação (1936), A escola e a vida (1942) e Como nasceu o Colégio Jacobina (1962) - profere discurso em homenagem ao centenário de nascimento de Edouard Claparède, muito tempo se passara. No texto cuidadosamente guardado na Associação Brasileira de Educação, parece que só foi possível escrever após a releitura atenta de seu álbum de viagem, pois algumas das imagens nele presentes estão ali reproduzidas. Desta vez, em meio a seleções, abandonos e esquecimentos, prefere enfatizar o que os unia, apagando as diferenças que existiram e persistiram dentre os muitos intérpretes da Escola Ativa:

E é com prazer que vejo que o impulso lá tomado pelo então jovem Prof. Piaget, não esmoreceu até hoje, pois vai brilhantemente continuando a difundir e enriquecer a mensagem que o Institut Rousseau, hoje Institut de Sciences de l'Education, vem desde 1912 enviando ao mundo para promover uma pedagogia científica que atenda a uma formação profunda do conhecimento da criança, baseada na sua psicologia. Foi, o Prof. Piaget, escolhido para substituir o Prof. Claparède na cátedra de Psicologia, e mais tarde assumiu a Direção do Institut, no falecimento do Prof. Bovet. Assim, é ele quem está levando ao mundo todo, a tocha acesa em 1912. Em breve, teremos o prazer de recebê-lo na nossa cidade. Para quem teve a felicidade de participar daquela colmeia laboriosa, naquele centro onde todos formávamos uma família, é reviver um pouco aquele ambiente, é voltar, também, aos seus anos de juventude. (LACOMBE, 1973, s/p) 
0 álbum de viagem enquanto documento a ser manuseado, visto, lido e relido, funcionou, neste momento, para a própria educadora viajante como suporte da memória, capaz de acionar as lembranças, apagar divergências, e mais uma vez, dar visibilidade ao vivido.

\section{Referências}

CARUSO, Andrea Soares. Traço de União como vitrine: educação feminina, ideário católico e práticas escolanovistas no periódico do Colégio Jacobina. Rio de Janeiro: Universidade do Estado do Rio de Janeiro, Programa de Pós-graduação em Educação (Dissertação de mestrado), 2006.

CARVALHO, Marta Chagas de. "A bordo do navio, lendo notícias do Brasil: o relato de viagem de Adolphe Ferrière". In: MIGNOT, Ana Chrystina; GONDRA, José (Orgs). Viagens Pedagógicas. São Paulo: Cortez Editora, 2007. p. 277-293.

“Pedagogia da Escola Nova, produção da natureza infantil e controle doutrinário da escola". In: FREITAS, Marcos Cezar de; KUHLMAN, Moysés (Orgs). Os intelectuais na história da infância. São Paulo: Cortez Editora, 2002. p. 373-408.

CLAPARĖDE, Edouard. A escola sob medida e estudos complementares sobre Claparède e sua doutrina por Jean Piaget, Louis Meyla, Pierre Bovet. Rio de Janeiro: Fundo de Cultura, 1959.

HOUSSAYE, Jean. "Pedagogias: importação-exportação". In: MIGNOT, Ana Chrystina; GONDRA, José (Orgs). Viagens Pedagógicas. São Paulo: Cortez, 2007. 294-314.

LACOMBE, Laura Jacobina. "Claparède, mestre e amigo". Rio de Janeiro: Arquivo da Associação Brasileira de Educação. (dat), 1973.

Álbum de viagem. Rio de Janeiro, Acervo da OMEP, (manuscrito), 1925.

MIGNOT, Ana Chrystina. Baú de memórias, bastidores de histórias: o legado pioneiro de Armanda Alvaro Alberto. Bragança Paulista: EDUSF, 2002.

"Claparède, mestre e amigo: memórias de travessias". Revista Interinstitucional Artes de Educar (RIAE), (Rio de Janeiro: Online), v 2, 253p., 2016a. Disponivel em: www.e-publicacoes.uerj. br/index.php/riae/article/download/25510/18107 Acessado em: 15 de março de 2017.

"Claparède, mestre e amigo: memórias de travessias". In. HERNÁNDES DIÁZ, José Maria (Coord). Influencias suizas em la educación española e iberoamenricana. Salamanca. Ediciones Universidad de Salamanca, 2016b. p. 355-364.

MOREU, Angel. "La influencia de la escuela de Ginebra em la primera fundamentación de la psicopedagogia española". In: HERNÁNDES DIÁZ, José Maria (Coord). Influencias suizas em la educación española e iberoamenricana. Salamanca. Ediciones Universidad de Salamanca, 2016. p. 53-68.

PERES, Eliane Therezinha. "O diabo inventou a escola? A escola ativa na visão de Adolpho Ferrière". In: Reunião Anual da Associação Brasileira de Pesquisa e Pós-Graduação em Educação (Anped), 25ạ, 2002, Anais cdrom. Caxambu, Rio de Janeiro, 2002. s/p.

RANUM, Orest. Os refúgios da intimidade. In: CHARTIER, Roger (Org). História da vida privada: da Renascença ao Século das Luzes. São Paulo, Companhia das Letras. V. 3, 1991. p. 211-266.

RUCHAT, Martine. "A escola de psicologia de Genebra em Belo Horizonte: um estudo por meio da correspondência de Edouard Claparède e Helene Antipoff". Revista Brasileira de História da Educação. no 17, p. 181-205, maio-ago. 2008.

SOLER MATA, Joan. "La Escuela Activa de Adolphe Ferrière em la pedagogia española e iberoamericana" In: HERNÁNDES DIÁZ, José Maria (coord). Influencias suizas em la educación española e iberoamenricana. Salamanca. Ediciones Universidad de Salamanca, 2016. p. 69-82.

STANG, Bernanete de Lourdes Streisky. 0 saber e o credo: os intelectuais católicos e a doutrina da 
Escola Nova (1924-1940). 2008. 298f. Tese (Doutorado em Educação). Programa de Pós-Graduação em Educação, Pontifícia Universidade Católica do Rio de Janeiro, Rio de Janeiro, 2008.

TORO BLANCO, Pablo Andrés. "Misión al Finis Terrae: Adolphe Ferrière y su viaje a Chile 1930". In: HERNÁNDES DIÁZ, José Maria (coord). Influencias suizas em la educación española e iberoamenricana. Sala- manca. Ediciones Universidad de Salamanca, 2016. p. 429-440.

VINÃO FRAGO, Antonio. "Viajes que educan". In. MIGNOT, Ana Chrystina; GONDRA, José (Orgs). Viagens Pedagógicas. São Paulo: Cortez, 2007. p. 15-38.

Recebido em: 10.05.2017

Aprovado em: 30.06.2017

Ana Chrystina Mignot é Doutora em Ciências Humanas/Educação pela PUCRS. Professora Associada da Universidade do Estado do Rio de Janeiro. Pesquisadora do CNPq. Cientista de Nosso Estado/Faperj. Procientista Faperj/UERJ. e-mail: acmignot@terra.com.br

Universidade do Estado do Rio de Janeiro / Programa de Pós-Graduação em Educação Rua São Francisco Xavier, 524, Bloco F, Sala 12037 - Maracanã, Rio de Janeiro RJ Telefone: (21) 98925-7459 